\title{
Research on the Teaching Practice of Ideological and Political Education in Blended College English Courses Based on POA
}

\author{
CHEN Qianqian \\ Zhejiang Yuexiu University, China \\ Received: July 2, 2021 \\ Accepted: August 29, 2021 \\ Published: November 30, 2021
}

To cite this article: CHEN Qianqian. (2021). Research on the Teaching Practice of Ideological and Political Education in Blended College English Courses Based on POA. Asia-Pacific Journal of Humanities and Social Sciences, 01: 3, 131-138, DOI: 10.53789/j.1653-0465.2021.0103.014

To link to this article: https: //doi.org/10.53789/ j.1653-0465.2021.0103.014

Abstract: As part of humanistic education in colleges and universities, college English course plays an important role in carrying out ideological and political education. College English courses should focus on the fundamental task of "building morality and cultivating people" and play its role in educating students. Starting from the high consistency between the production-oriented approach and the notion of ideological and political education, the present study adopts the Online and Offline Blending Teaching Mode(OOBTM) to explore the teaching practice of ideological and political education. Under the guidance of the production-oriented approach, the college English teaching can effectively achieve overall educational goals and cultivate students to talk about Chinese stories and spread Chinese culture. Knowing Chinese and Western cultural differences can enable students to establish a sense of mutual nationalization of Chinese and Western civilizations.

Keywords: POA; ideological and political education; blended teaching; Chinese culture

Notes on the contributor: CHEN Qianqian holds a master's degree in arts. She is a lecturer at Zhejiang Yuexiu University of Foreign Languages, and her academic interest lies in foreign language teaching.

\section{基於產出導向法的大學英語課程 思政混合式教學實踐研究}

\author{
陳倩倩 \\ 浙江越秀外國語學院
}

摘 要: 大學英語課程作為高校人文教育的一部分, 是課程思政實施的重要陣地。大學英語教學 應圍繞“立德樹人” 的根本任務, 發揮其育人作用。“産出導向法” 是具有中國特色的外語教育理 
論。本文從產出導向法理念與課程思政的高度契合性出發, 采用線上線下混合式教學模式, 探討 大學英語課程思政教學實踐。產出導向法理論指導下的大學英語課程思政教學能有效實現全程 全方位育人目標, 培飬學生講好中國故事、傳播中國文化的能力。認識中西文化差異能夠使學生 樹立中西文明互鑒意識。

關鍵詞: 產出導向法; 課程思政; 混合式; 中國文化

\section{引言}

高校課程思政是高校加強人才培飬的重要舉措。2016 年,習近平總書記在全國高校思想政治工作會議 中發表重要講話, 提出要將立德樹人作為高校的立身之本。 ${ }^{1}$ 為落實立德樹人的根本任務, 2020 年,教育部印 發的《高等學校課程思政建設指導綱要》( 以下簡稱《綱要》) 中指出, “各類課程與思政課程同向同行,將顯 性教育和隱性教育相統一,構建全員全程全方位育人大格局”。②

大學英語課程作為高校人文教育的一部分, 兼具工具性和人文性。語言是文化的載體。學生在接觸大 量的英文材料的同時, 也需面對國外複雜多元的價值觀和意識形態。世界多元文化輸人過程中的跨文化比 較與思辨為外語課程思政教學打開了新的視角。如何通過語言意識形態和文化價值取向的鑒別,從而進行 有效的價值觀引導, 是大學英語教學的責任和使命。大學英語作為課程思政的重要陣地, 應幫助學生樹立 正確的價值觀, 堅定中國立場, 讋證地認識和評價外來文化。 ${ }^{3}$ 根據最新版的《大學英語教學指南》( 以下簡稱 《指南》), 大學英語應注重課程思政教學, 圍繞立德樹人這一根本任務, 將社會主義核心價值觀融人教學内 容, 培養學生中國文化理解能力和傳播意識, 同時加強中外文化異同的認識, 培飬學生家國情懷和融通中西 的能力。 ${ }^{(4)}$

\section{一、大學英語課程思政研究現狀}

目前國內學者對大學英語課程思政的研究主要集中在宏觀層面。劉建達構建了基於課程思政的大學

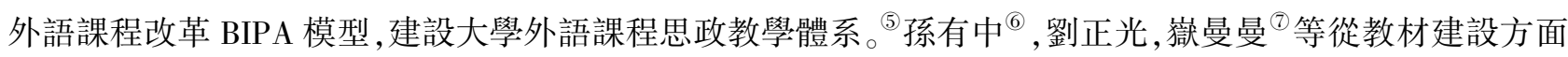
探討外語課程思政教材設計的原則與方法,推動教學理念與教學路徑的更新。蔡基剛展開對大學英語課程 思政實施路徑的探討。 ${ }^{8}$ 文秋芳提出外語課程思政的實施框架, 為外語課程思政教學提供了具體的操作建 議。 ${ }^{9}$ 以上研究構建了大學英語課程思政教學的實施框架與實施路徑,從理念轉變, 教材建設,教學方法更新 等方面為大學英語課程思政教學的開展指明了方向。

在具體的教學實施層面,佑曼曼,劉正光㘓述了混合式教學與“立德樹人”課程思政的高度契合性,充分 論證了混合式教學能更好地實現課程思政隱性教學目標。 ${ }^{\circledR}$ 楊婧在現有教材的基礎上,著重探討大學英語思 政教學的具體實施方案。 ${ }^{\mathbb{1} 1}$ 總體看來, 目前的大學英語課程思政教學研究依然大體基於宏觀的角度,少有具 體教學理念和方法指導下的課堂教學實踐系統研究和具體操作方案。因此, 本文嘗試從教學實踐出發, 以 產出導向法為理論支撐,探討大學英語課程思政教學的實踐方案。

\section{二、POA 理論與大學英語課程思政的契合性}

產出導向法(Production-oriented Approach, POA) 是文秋芳教授團隊提出的具有中國特色的外語教育理 
論創新成果, 對中國外語教育改革具有深遠的影響。POA 理論體系涵蓋教學理念, 教學假設和教學流程三 大部分。

教學理念中的“學習中心說”強調課堂教學活動必須促成有效學習的發生,換言之,教師在教學環節的 設計過程中應考慮學生能學到什麼。“學用一體說”針對的是大學英語課堂教學中長期以來的“學用分離” 現象, 提倡輸人性學習與產出性成果的緊密結合, 主張邊學邊用。因學習中心說和學用一體說與課程思政立 德樹人的育人目標高度契合,在大學英語課程思政教學過程中,教師應充分挖掘每單元的思政元素,使學生 將獲得的接受性知識轉化為產出能力。在學用結合的課堂活動中, 著重關注學生是否達到設定的育人目 標, 以潤物細無聲的方式培養學生的家國情懷,使其樹立正確的價值觀。

“文化交流說” 是教學内容選擇的依據, 主張文化交流互鑒, 強調不同國家與民族互相尊重彼此文化,加 強交流, 平等對話。 ${ }^{13}$ 該理念與大學英語課程思政立德樹人的根本任務不謀而合。根據《綱要》和《指南》 (2020) 中對於課程思政的要求,要加強中國傳統文化教育,引導學生深刻理解中國傳統文化的思想精髓, 服 務中國文化對外傳播,實現中外文明交流互鑒。“關鍵能力說”的前身是“全人教育說”。經過調整後的“關 鍵能力說”包括語言、學習、思辨、文化、創新和合作六種關鍵能力, 旨在更好地貫徹立德樹人的任務, 實現全 程全方位育人目標。

綜上所述, 產出導向法的理念與大學英語課程思政的要求和立德樹人的根本任務高度一致,這表明將 產出導向法理論運用於大學英語課程思政教學的實踐具有可行性。鑒於此,本文以產出導向法為理論指 導, 以《新目標大學英語》為例,運用線上線下混合式教學, 探討大學英語課程思政教學實踐。

\section{三、基於產出導向法的大學英語課程思政教學設計}

產出導向法的教學流程包括由驅動一促成一評價組成的若幹循環鍕。教學實踐以單元為教學單位,采 用平行推進式,一個單元設計一個大產出目標, 然後將其分解為若幹個小產出目標, 有前後邏輯關系但又各 自相對獨立的小產出目標可形成完整的“驅動一促成一評價” 循環。 筆者選取了《新目標大學英語》第二冊 第一單元 Understanding Chinese Culture and Tradition 為例進行教學設計和實踐。根據 POA 教學流程, 筆者借 助“雲班課”平臺構建了基於產出導向法的大學英語課程思政混合式教學框架,如圖 1 所示。

由於筆者所在的學校是一所外國語學院, 因此大學英語課程課時相對充裕, 周課時為 4 ,每單元安排 8 課時, 為充分展開 POA 教學活動提供了課時保障。筆者進行了為期兩周的教學實驗,對象為金融學院投資 學專業一年級學生,並於結束時在雲班課搜集學生對於本次教學實驗的反饋。

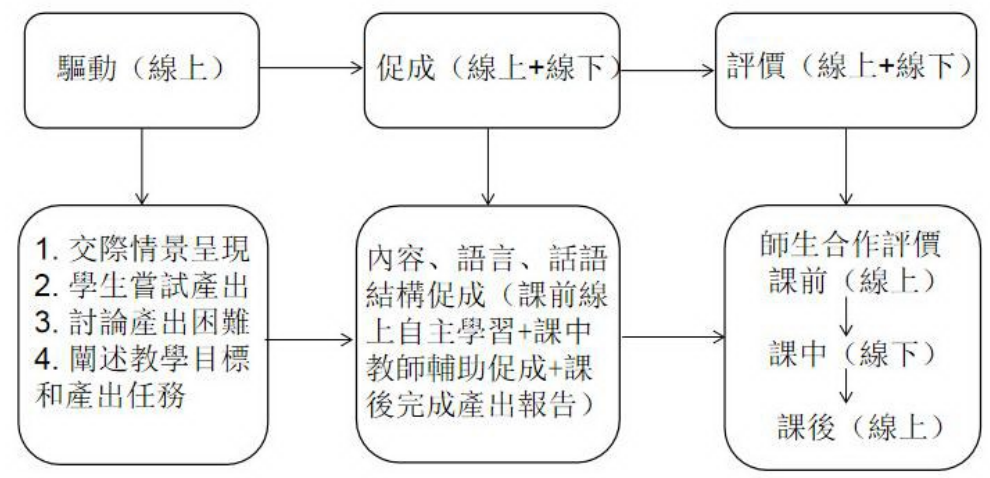

圖 1 基於產出導向法的大學英語課程思政混合式教學框架 


\section{（一）教學總目標}

該單元的主題是中國優秀傳統文化, 本次教學實践主要選取了儒家思想這一主題作為案例, 以中國傳 統文化為思政切人點展開教學活動。本單元語言目標為: (1) 能用英語闡述儒家思想內涵和重要觀點; (2) 能運用擴展定義寫作的方法閭述定義, 掌握對比與比較的方法。育人目標為: (1) 學生通過學習和產出, 能 用英語闆述儒家重要思想, 講好中國故事, 樹立文化自信; (2) 通過學習, 樹立不同文化之間平等交流, 文明 互鑒的意識。

\section{(二) 教學設計}

本單元總產出任務為: 假如你是在美國留學的中國學生, 請你在學校中西文化交流論壇上發帖, 題為儒 家思想與中西文化平等對話。筆者將總產出任務分為兩個子任務 (圖 2)。

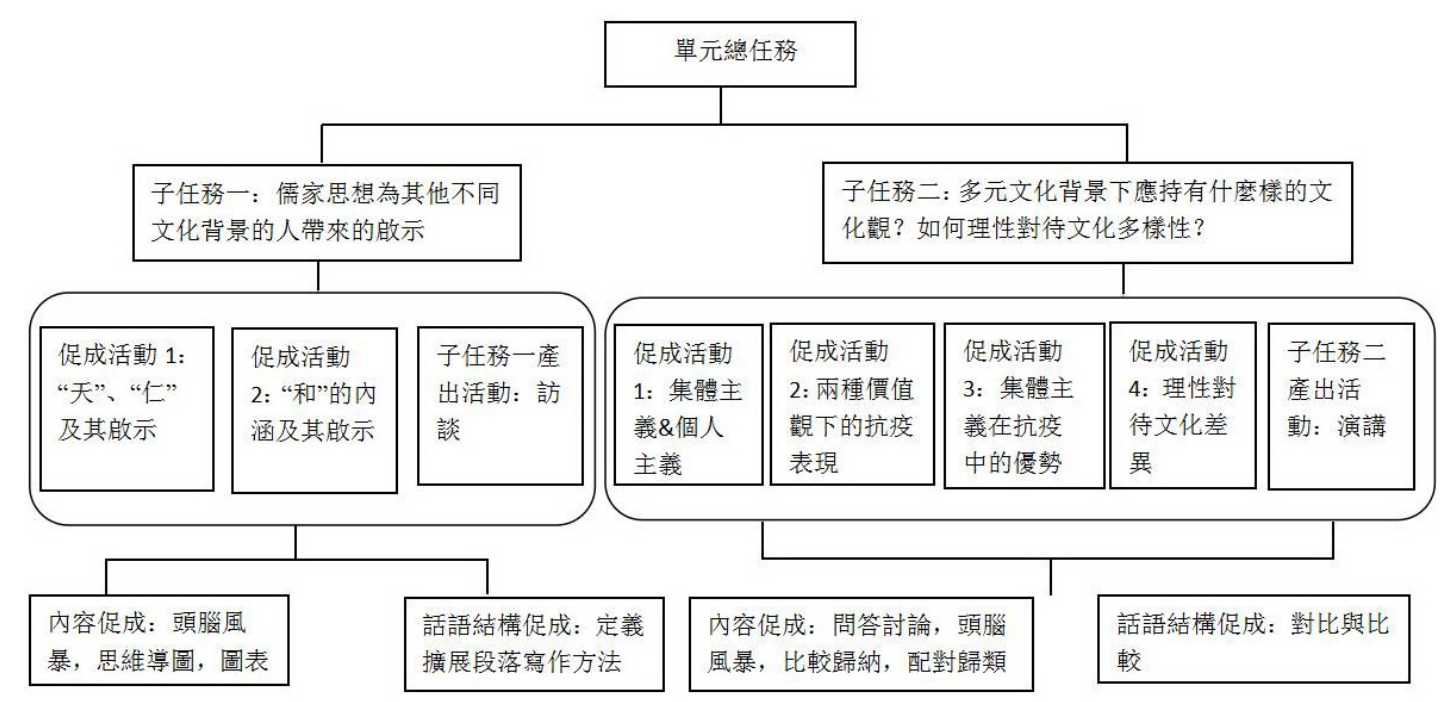

圖 2 促成活動設計

子任務一:儒家思想為其它不同文化背景的人帶來的啟示; 子任務二:多元文化背景下應持有什麼樣的 文化觀? 如何理性對待文化多樣性? 兩個大的產出子任務各自形成驅動一促成一評價的循環, 最終實現大 的產出目標。任務分解的目的是為了充分發揮教師的中介作用,為學生搭建縱向 “腳手架”。任務是否進一 步分解, 取決於學生水平。如學生還有難度, 則應進一步分解。 ${ }^{15}$ 鑒於學生基礎相對薄弱, 在實際教學過程中 筆者進一步將子任務一分解為: (1) 美國人眼中的儒學及其背後的儒家思想精髓; (2) 你認為這些儒家思想 給其它不同文化背景的人什麼樣的啟示? 子任務二可進一步分解為: (1) 以儒家文化為代表的中國文化和 西方文化之間在價值觀上存在的差異 (以集體主義和個人主義為視角); (2) 儒家思想為多元文化視角下理 性對待文化差異帶來的啟示。

\section{(三) 教學流程}

1. 子任務一:儒家思想為其它不同文化背景的人帶來的啟示。

\section{驅動}

驅動環節通過教師設計具有潛在交際價值的任務, 使學生在產出的過程中意識到困難和不足, 從而調 動學習積極性。筆者先向學生呈現交際場景 (線上雲班課呈現) : 你的美國朋友發郵件給你表示對儒家思想 很感興趣, 想跟你探討儒家文化, 以及儒家思想給美國和其它文化背景的人帶來的啟示。請學生嘗試產出, 
以書面報告的形式給美國朋友回一封郵件, 上傳雲班課平臺, 並就產出過程中遇到的困難請學生在線上進 行討論,師生共同發現了產出過程中暴露的問題: (1) 學生對儒家思想缺乏了解。(2) 學生不知道如何用英 文闆述儒家相關思想。以此促使學生產生 “饑餓感”, 激發學習欲望, 即文秋芳 POA 理論強調的輸出驅動假 設。之後筆者闡述教學目標和產出任務。

\section{促成}

促成環節幫助學生 “逢山開路、遇水搭橋”, 有針對性地為學生產出提供腳手架。文秋芳指出, 促成環節 既包括輸人也包括輸出，二者不進行明確區分，促成活動應體現“學用一體”的理念。根據“輸人促成假設”, 輸人要為明確的產出目標服務。教師應根據產出需要, 從輸人材料中挑出有利於產出的部分, 供學生選擇 性學習。促成環節應至少包括內容、語言和話語結構三方面。由 ${ }^{10}$ 於篇幅所限,本文主要䦴述内容和話語結 構兩方面的促成活動。

子任務一的輸人材料由課文 Text A 和補充材料組成。筆者於課前先將補充材料發布在雲班課平臺, 供 學生課前自主學習。課文主要講美國人如何理解儒家思想精髓, 學生通過閱讀課文,完成課後第一部分練 習。該部分練習以概念圖的形式概括了美國人眼中的儒家思想核心要素。概念圖的優勢在於給學生提供 一個框架, 以便快速把握文章的結構, 使輸人學習有利於輸出。通過關鍵詞 (the sacred in the secular, harmony）引伸出美國人對於儒學的關注點: 仁、和。教學活動設計圍繞美國人對於儒學的關注點和背後的儒家 思想精髓以及對其它文化的啟示展開。接著教師請學生快速閱讀文章 2-4 段並討論: 為什麼作者認為儒家 思想不是宗教? 儒家思想和宗教的區別是什麼? 你認為儒家思想是宗教嗎? 學生小組討論快速找出文章 中相應的信息。在此過程中學生發現課文所涉相關内容並不足以支撐更深層次的討論。此時筆者適時引 人補充材料 Confucian Thought on Heaven and Humanity, 該文章選自葉朗《中國文化讀本》。同時, 筆者向學生 介紹本單元的閱讀和寫作重點, 即對複雜概念和定義的理解和對於定義的擴展寫作, 寫作技能是閱讀技能 的延伸。學生小組討論找出儒家關於 “天” 的思想相應詞句和表達, 並通過頭腦風暴提煉要點, 繪制思維導 圖, 最後根據思維導圖總結出定義擴展段落的寫作要點, 教師在此過程中的每一步都提供相應的幫助。本 環節的輸出練習為根據思維導圖和寫作要點複述並嘗試產出: 什麼是孔子關於天的思想? 你認為儒家思想 中關於天的理念給人們什麼樣的啟示?

接著學生找出儒家關於“仁”的思想要點,依舊采用提煉重點繪制思維導圖的方法,總結定義寫作要點 並派小組代表複述。需要強調的是, 在此環節, 筆者根據各小組學生基礎不同, 嘗試選擇性給予協助。比 如, 基礎相對較好的小組少給腳手架, 而對於基礎薄弱的同學多給予幫助, 或者請組內基礎較好的學生為基 礎相對薄弱的學生提供腳手架, 如此既能使弱生得到相應的幫助使之順利產出, 又能激發強生的學習積極 性和自信心。接下來, 教師請學生討論儒家的 “天” 與 “仁”之間的關系,引導學生闡述天道自然是人倫道德 的基礎, 天地為人與萬物之父母引伸出儒家 “仁民而愛物” 的普世道德。因此部分的課後產出任務為儒家思想 中的“天”與“仁” 的內涵及其對其它文化背景的人的啟示, 要求學生以書面報告的形式上傳到雲班課。

學生在兩輪產出之後,已基本掌握了對於定義的擴展寫作。下一步, 筆者請學生例舉出儒家思想中關 於“和”的名句及其英文翻譯 (雲班課課前完成)。並進一步引導學生歸納討論“天人合一”; “禮之用, 和為 貴”; “家和萬事興”; “君子和而不同, 小人同而不和” 等名句從哪些角度闠述了 “和” 的內涵。學生以小組為 單位討論並派代表匯報總結了人與自然的關系, 人與人之間的關系以及不同文化之間的關系。值得注意的 是 “和而不同” 的理念強調如何對待文化差異, 為子任務二做了鋪熱。接著結合課文練習 2B 部分, 以圖表的 形式挖掘美國人從不同角度出發理解的“和”, 並討論: 你認為儒家 “和” 文化給人們什麼樣的啟示? 本環節 產出練習為運用定義擴展寫作的方法談談對於 “和” 的理解。子任務一的最終產出活動要求學生結合以上 所學儒家思想的觀點, 以及課文中美國人對於儒學的看法, 以小組為單位進行采訪, 一人扮演美國學生 inter- 
viewer, 另外幾人扮演中國學生 interviewee, 為了降低任務難度, 小組中每一位 interviewee 認領一個儒家思想 及其啟示, 最後錄制視頻上傳到雲班課。

子任務一實現了三步走,遵循 POA “記憶、理解、應用、分析、評價和創造” 的認知規律。 ${ }^{13}$ 首先教師帶領學 生通過閱讀材料掌握理解複雜概念的方法和定義擴展段落寫作技巧,此為記憶、理解階段; 產出練習要求闡 述對於“和”的理解,此為應用,分析階段,整個過程符合 POA 促成漸進性的原則。

子任務二:多元文化背景下應持有什麼樣的文化觀? 如何理性對待文化多樣性?

驅動

子任務二呈現的情景為: 武漢疫情爆發初期, 外媒質疑中國的封鎖隔離政策侵犯了人權和自由 (圖片呈 現), 你怎麼認為? 學生圍繞以下幾個問題展開討論: (1) 為什麼會導致這種沖突和誤解? 中西文化在價值 觀上有何差異?（2）儒家思想為多元文化視角下理性對待文化差異帶來的啟示。學生仍然通過雲班課嘗試 產出, 並討論產出困難, 教師點評。

促成

促成部分的輸人材料為筆者選自 China Daily 的文章 Understanding culture is key to understanding political differences (材料提前發布於雲班課供學生自主學習)。課堂活動第一步, 根據文章內容兩人一組結對討論:

(1) Why do the author's fellow countrymen have become doubtful about United States' highly effective government since the outbreak of the Covid-19 pandemic? (2) What may be the root cause to conflicts and misunderstanding between two cultures? 通過討論得出中西文化體現出集體主義和個人主義的差異。因此該部分的話語結構促 成是通過 comparison \& contrast 的方法對比兩種價值觀的差異。第二步, 教師在講解對比和比較的方法以及 相關知識的基礎上, 協助學生運用對比和比較的方法完成圖表練習, 比較集體主義和個人主義的差異, 總結 文章運用的 subject-by-subject 的比較方法。該練習的目的是幫助學生快速概括歸納文章中有利於產出的 信息,進行選擇性學習。

第三步,集體主義如何體現在中國人民抗疫鬥爭中 (課前雲班課發布視頻: The lockdown-one month in Wuhan), 通過頭腦風暴全班討論出提示詞 (全國一盤棋、醫護人員、志願者、解放軍、社區工作者、武漢及全國 人民等) 並由此小组討論發散思維, 最後小組選派代表匯報, 教師通過教學課件呈現疫情初期中國人抗疫表 現以完善補充學生的觀點。接下來用同樣的方法討論疫情下個人主義的體現,進一步引導學生探討西方媒 體及民眾強調的個人權利和自由如何體現在抗疫過程中。本環節的課外輸出活動為: 用比較的方法分析集 體主義和個人主義, 以及兩種價值觀為主導的文化背景下中國和西方在抗疫過程中的表現。第四步, 鑒於 外媒對中國疫情隔離管控政策的質疑,你的看法如何? 你認為集體主義在中國抗疫鬥爭中體現出什麼樣的 優勢和有效性? 該環節筆者提供了英國學者 John Ross 的采訪視頻, 采訪中 John Ross 表達了其對於中國抗 疫的肯定和對西方人權的質疑。考慮到學生基礎, 除視頻外配上文字。教師引導學生根據采訪的技巧, 聚 焦問題和回答。教師引導學生關注中國抗疫的積極成效, 體現了社會主義制度和治理體系的優越性, 展現 出中國人民崇尚集體主義和家國情懷的中國精神。本環節輸出練習為角色扮演: 小組為單位分別扮演外國 記者和中國受訪者,每一個受訪者負責一個問題,之後小組成員角色互換。

第五步, 你認為在多元文化背景下應如何理性對待文化差異? 儒家思想為多元文化背景下理性對待文 化差異帶來什麼樣的啟示? 該步驟中筆者以抽查的形式請學生先口頭複述子任務一中 “和而不同” 的理念, 接下來提供的材料為習近平在亞洲文明對話大會開幕式上的主旨演講。對文中具體措施和建議采用配對 歸類的方法加深對有用信息的理解。最後小組討論並產出: 在和而不同理念指導下的多元文化觀中, 什麼 是 “和” (保留自己的優秀文明傳統), 什麼是 “不同” (兼收並蓄, 容納不同文明的存在) ? 你認為應如何對待 中國傳統文化? 如何實現不同文明平等對話? 子任務二課後產出活動為演講, 中西文化差異與多元文化發 
展。該部分產出的目的是使學生意識到中國文化 “和而不同”體現出的強大包容性,及當今世界構建人類命 運共同體的迫切需求,培養學生思辨能力。最終學生完成大產出任務。

整個促成環節設計遵循文秋芳教授提出的精准性、多樣性和漸進性。 ${ }^{19}$ 促成活動高度匹配產出目標, 輸 人活動涵蓋文本閱讀和視頻觀看學習,輸出活動包括口頭產出和書面報告。交際形式分為訪談, 討論, 演講 等。此外, 課堂活動實現了個人活動, 兩人結對, 小組活動和全班討論等多種形式。就漸進性而言, 促成活 動體現了從接受性技能到產出型技能的轉變過程,遵循 POA 認知規律。

\section{（四）師生合作評價}

產出導向法主張師生合作評價 ( TSCA)。在教師的專業引領下,學生邊評邊學,評學結合。評價包括即 時評價和延時評價。本文即時評價體現在每一個子任務的小任務環節,隨時對學生產出進行評價。延時評 價包括對學生課後完成的產出任務進行評價。此處主要闆述延時評價。依據文秋芳 TSCA 評價步驟, 以最 終的總產出任務為例, 筆者於課前從雲班課上傳的學生產出報告中選出典型樣本。為保證樣本的可改, 可 評性, 該樣本處於中等質量水平。從教學目標出發, 内容, 語言, 和話語結構三方面制定評價標准和步驟。 課堂上,學生根據評價標准和重點,對典型樣本進行獨立評價, 小組討論, 到大班討論。最後學生將自評和 互評修改後的終稿提交批改網進行機器評分。師生合作評價能為學生提供專業精准的指導, 使學生課後自 評和互評更有方向和針對性。贵

\section{四、教學反思與結語}

通過兩周的教學實踐,筆者發現產出導向法指導下的大學英語課程思政教學效果相較於傳統課堂具有 明顯優勢。首先, 學生學習積極性顯著提高, 之後雲班課的學生反饋表明以產出為導向的學習使得學生 “願 意學”, 比傳統課堂“學習目的更明確”, “學習過程中收獲很多”。其次, 育人目標達成更為有效。學生通過 輸人性學習和產出任務的完成, 特別是通過循序漸進的子任務, 理解並學會用英語閭述中國優秀儒家文化, 講好中國故事,潛移默化中樹立文化自信,並“加深對中西文化差異的認識”, “學會尊重不同的文化”,實現 文明互鑒。第三,產出為導向的學習使得學生有更多語言運用的機會,教師的中介作用也提高了學生的產 出質量,真正實現了“有效學習”。

同時, 由於教學時間和學生語言水平的限制, 子任務中的一些教學環節設計還有待改進。部分基礎薄 弱學生反饋“有些力不從心”, 因此教師應根據學生的語言水平適時調整腳手架使用策略, 幫助學生增強自 信心, 更好地完成產出任務。此外, 由於課堂教學時間受限, 驅動和部分評價環節在雲班課上完成, 加上課 後小產出任務過多使得學生反映“負擔重”、“占用太多課外時間”。鑒於此, 教師在活動設計和課後任務布 置中應適當考慮學生的主觀想法。

筆者以產出導向法為指導的大學英語課程思政混合式教學研究, 是對大學英語更好實現立德樹人根本 任務的初步探究。課堂實踐證明產出導向法能有效達成育人效果, 滿足大學英語工具性與人文性的雙重目 標。但同時由於時間和筆者水平的限制, 該研究尚有很多不足之處, 基於產出導向法的課程思政研究也需 要更多的實踐以證實其有效性。

\section{注釋}

(1) 習近平在全國高校思想政治工作會議的重要講話, 《人民日報》2016 年版。

(2) 教育部:《高等學校課程思政建設指導網要》, 2020 年版。 
(3) 楊金才:《新時代外語教育課程思政建設的幾點思考》,《外語教學》2020 年第 6 期。

(4) 教育部高等學校大學外語教學指導委員會: 《大學英語教學指南》, 高等教育出版社 2020 年版, 頁 23-24。

(5) 劉建達:《課程思政背景下的大學外語課程改革》,《外語電化教學》2020 年第 6 期。

(6) 孫有中:《課程思政視角下的高校外語教材設計》,《外語電化教學》2020 年第 6 期。

(7) 劉正光、猚曼曼:《轉變理念, 重構內容, 落實外語課程思政》,《外國語》2020 年第 5 期。

(8) 蔡基剛:《課程思政與立德樹人內涵探索一以大學英語課程為例》,《外語研究》2021 年第 3 期。

(9) 文秋芳:《大學外語課程思政的內涵和實施框架》,《中國外語》2021 年第 2 期。

(10) 猚曼曼、劉正光:《混合式教學契合外語課程思政:理念與路豩》,《外語教學》2020 年第 6 期。

(11) 楊婧: 《大學英語課程思政教育的實践研究》,《外語電化教學》2020 年第 4 期。

(12)文秋芳:《構建產出導向法理論體系》,《外語教學與研究》2015 第 4 期。

(13) 文秋芳:《産出導向法: 中國外語教育理論創新探索》, 外語教學與研究出版 2020 年版, 頁 45-46。

(14) 文秋芳:《“產出導向法”與對外漢語教學》,《世界漢語教學》2018 年第 3 期。

(15) 曹巧珍: 《“産出導向法”之教師中介作用探析一<以新一代大學英語>第二冊第四單元為例》, 《中國外語教育》2017 年第 1 期。

(16) 文秋芳:《構建產出導向法理論體系》,《外語教學與研究》2015 第 4 期。

(17) 李存山: 《天地信仰與儒家的普世道德》,《國際儒學 (中英文) 》2021 年第 1 期。

(18) 邱琳:《產出導向法促成活動設計》, 外語教學與研究出版社 2020 年版, 頁 73-76。

(19)文秋芳:《“產出導向法”教學材料使用與評價理論框架》,《中國外語教育》2017 年第 2 期。

(20)文秋芳:《“師生合作評價” : “産出導向法”創設的新評價形式》,《外語界》2016 年第 5 期。 